Šefik Behrem

Bahrudin Hrnjica

https://doi.org/10.21278/TOF.42Si106

ISSN 1333-1124

eISSN 1849-1391

\title{
ESTIMATION OF HEAT TRANSFER COEFFICIENT DURING QUENCHING STEEL IN WATER
}

\begin{abstract}
Summary
The paper presents the process of two-dimensional axisymmetric quenching of cylindrical samples in water at $40{ }^{\circ} \mathrm{C}$. Experimental work consists of quenching three dimensionally different cylindrical probes. The dimensions of the probes are: $\phi 25 \times 50$, $\phi 50 \times 150$ and $\phi 75 \times 225 \mathrm{~mm}$. Three measuring points are $1.5 \mathrm{~mm}$ below the cylinder surface positioned at the cylinder height, whereas the fourth measuring point is in the center of gravity of the cylinder. The quenching was conducted in strict controlled rate of water flow at the cylinder head. The problem of the task belongs to inverse problems of heat conduction, or ill posed problems, so that the solution to the problem leads to a sufficiently accurate estimate of the unknown heat transfer coefficient, imposed on the outer surface of the cylinder. Computer model solutions use experimental results of temperature measurements to minimize errors between computer calculations and measured temperature values in the same place. The selected solution algorithm is a hybrid algorithm that consists of a combination of three different algorithms of solution, connected into a single unit.
\end{abstract}

Key words: $\quad$ Cylindrical probe, steel quenching, optimization, inverse heat transfer, heat transfer coefficient

\section{Problem description}

In regard to the quenching of cylindrical samples, many published studies are mostly based on 1D axisymmetric problems of older ([1], [2], [3] ...) and more recent ([9], [10]) date, while $2 \mathrm{D}$ axisymmetric and $3 \mathrm{D}$ problems are very rare or none ([11], [12], [13]). Fig. 1 depicts vertical immersion of the cylinder with diameter $D$, height $H$, initial temperature $\approx 850{ }^{\circ} \mathrm{C}$, and rate $w_{a}=0.025 \mathrm{~m} / \mathrm{s}$, in the cooling fluid that flows upwards with speed $w_{1}=0.336 \mathrm{~m} / \mathrm{s}$. During the immersion of the probe into the cooling fluid, temperature values are continuously measured in four points $(1,2,3,4)$ of the probe, using embedded thermoelements. Fig. 1 shows qualitative values of tested physical model. Based on the obtained values of temperature in the probe, heat transfer coefficient is estimated from the surface of submerged probe to the cooling fluid. The idea for the paper was created according to [1], [2] and [5]. 


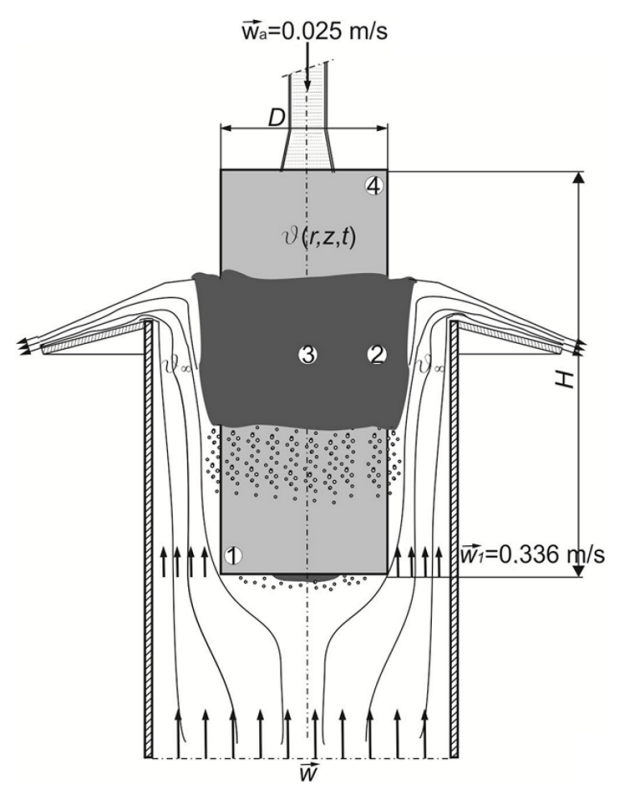

Fig. 1 Problem description

\section{Experimental setting}

Experimental setting consists of quenching of three dimensionally different cylindrical probes. The material of the probes is steel AISI 304 without crystal conversion. Quenching was conducted in strict controlled water flow rate of $0.336 \mathrm{~m} / \mathrm{s}$ around the cylinder, as well as maintenance of water temperature within a maximum of $40 \pm 2.5{ }^{\circ} \mathrm{C}$ during cylinder quenching. The experiment consists of the following: charging the system with quenchant, heating and maintenance of the quenchant at $40{ }^{\circ} \mathrm{C}$ with circulation, vertical dropping of cylindrical probe in the center of the heating furnace using mechanical drive, closing and warming the probe in nitrogen atmosphere up to $850{ }^{\circ} \mathrm{C}$ for a maximum of four hours, opening furnace lower door and vertical descent with a simultaneous start of data acquisition, dropping probes at a constant rate in the cooling bath, quenching the probe to the steady state with the interruption for data acquisition, and raising the probe to the starting position, which marks the end of the experiment. Realistic and schematic display of the measurement line is shown in Fig. 2 and 3, [12].

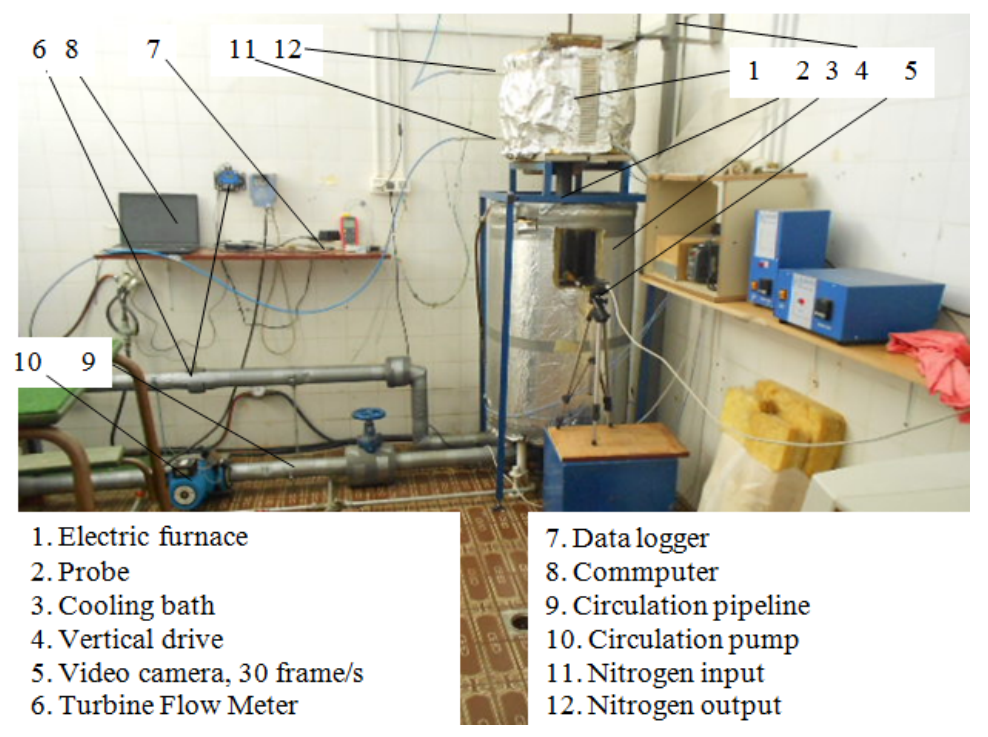

Fig. 2 Laboratory layout measuring lines 
1. Cylindrical probe

2. Electrical furnace with automatic

3. Coaxial cooling bath

4. The glass tube (space for quenching and possibility video recording)

5. Mechanical drive (up, down)

6. Electrical motor, $A C$ converter-6P

7. Protection tube for $4 \times T C$ (transferred weight of the probe)

8. Circulation pump (AC converter)

9. Circulation pipeline

10. Turbine flowmeter with display

11. Dato acquisition (NI USB 9213)

12. $P C$

13. Set for maintaining the temperature of the circulation fluid, $40 \pm 2.5^{\circ} \mathrm{C}$

- Electical heater of quenchants

$(2 \times 1800 \mathrm{~W})$

- Pt 100 Sonda

- spiral cooling pipe $(18 \mathrm{~m})$

14. Extension leads $(4 \times K-T C)$

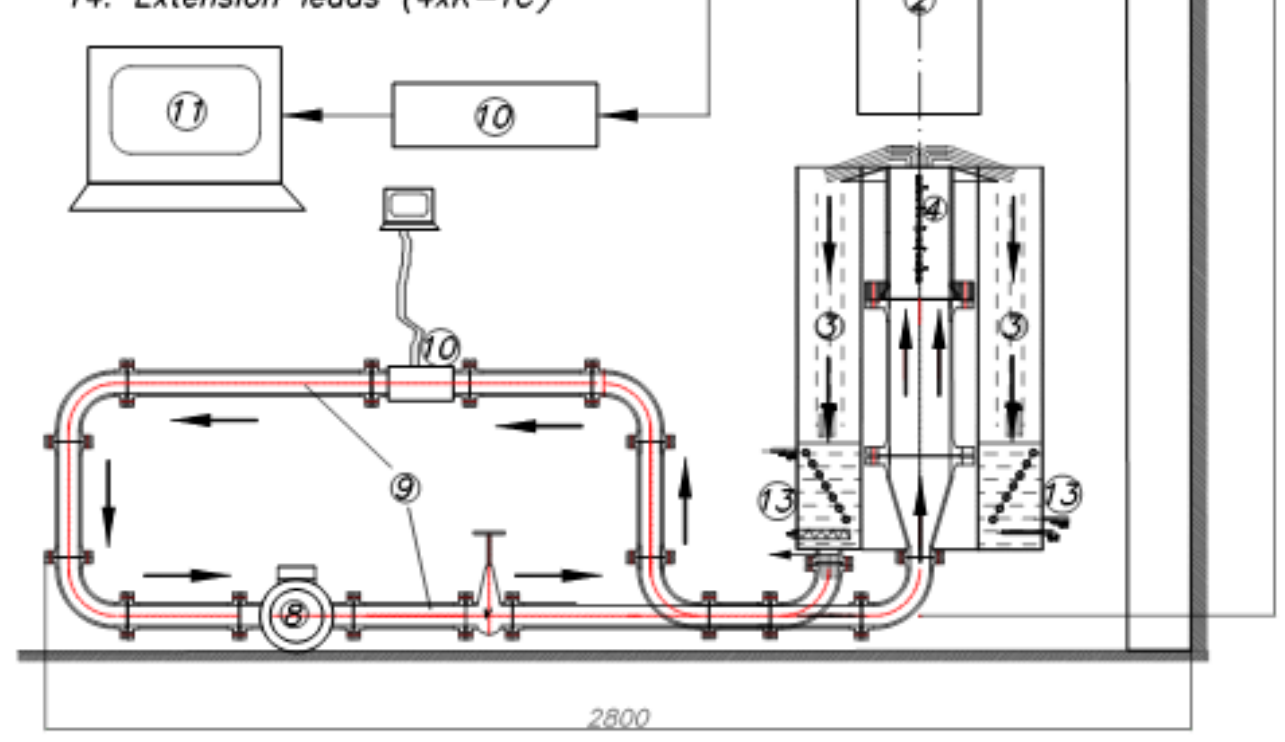

Fig. 3 Schematic drawing of measurement lines

The rate of data acquisition is two samples/seconds on high-precision mode, simultaneously from four points inside the cylinder. Data collector is NI USB-9213 module with 16-channel thermocouple inputs. Three measuring points are $1.5 \mathrm{~mm}$ below the cylinder surface arranged at the height of the cylinder, while the fourth measuring point is in the center of gravity of the cylinder. Technical drawing of the test cylinder $\phi 50 \times 150$ is shown in Fig. 4, while the actual display of the probe $\phi 75 \times 225$ is shown in Fig. 5. The other two probes have the same arrangement of thermocouples. 


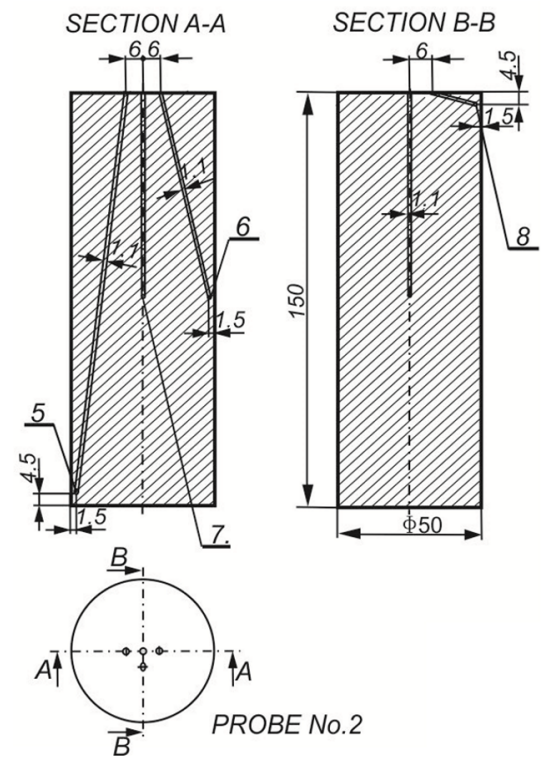

Fig. 4 Technical drawing of the test cylinder $\phi 50 \times 150$

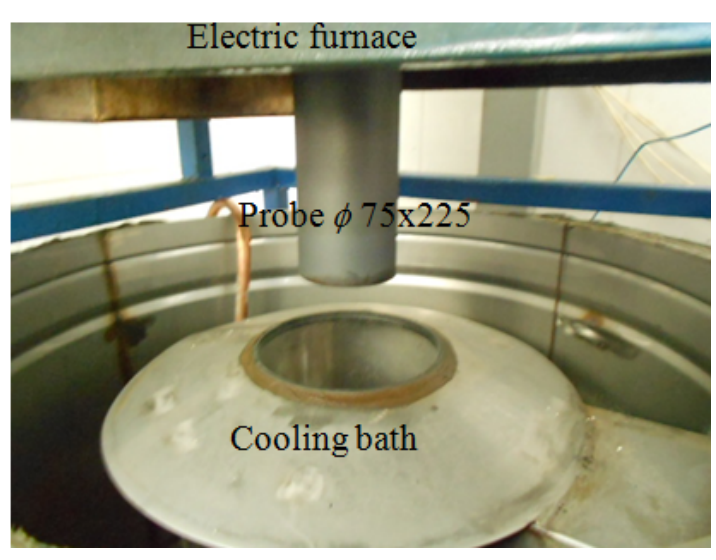

Fig. 5 Laboratory view of the test cylinder $\phi 75 \times 225$ above the space for quenching

The measurement results, or cooling curves, for the probe $\phi 75 \times 225$ are shown in Fig. 6, whereas cooling curves for the other two probes are shown in the comparison of the measured and simulated results [12].

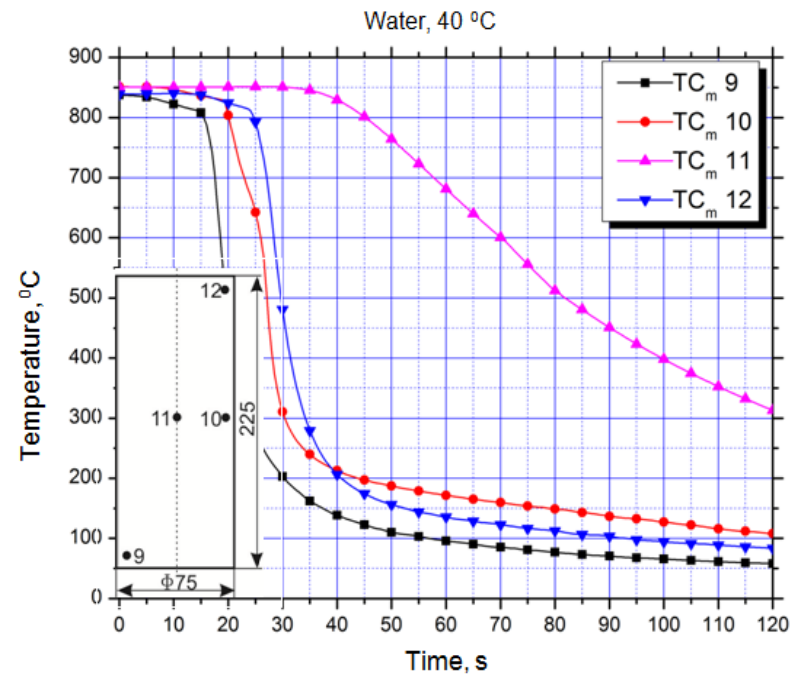

Fig. 6 Cooling curves for the probe $\phi 75 \times 225$ in marked points $9,10,11$ and 12

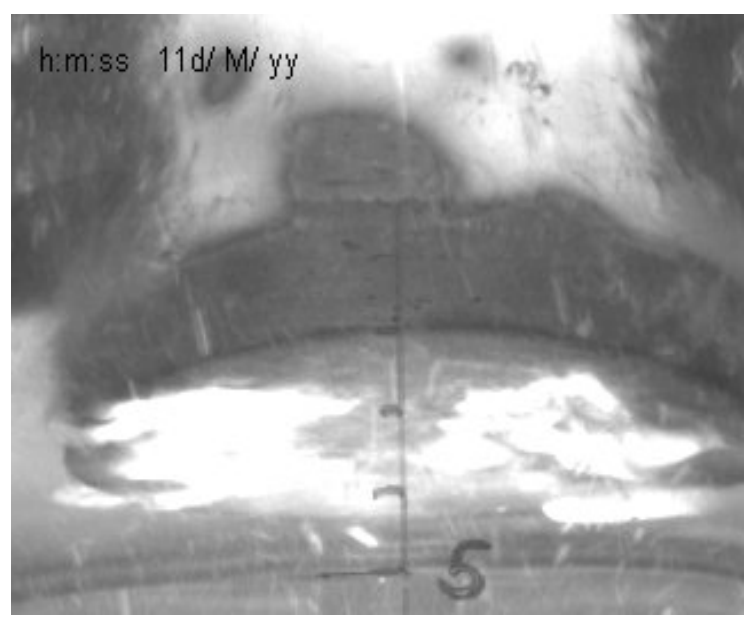

Fig. 7 Video image of the vapor film on the surface of the probe $\phi 75 \times 225$ in $t=1.75 \mathrm{~s}$ after immersion [12]

Mark $\mathrm{TC}_{\mathrm{m}}$ in Fig. 6 represents thermocouple measurement in selected points of individual probes. Points 1, 2, 3 and 4 are marked in the probe $\phi 25 \times 100$, points 5, 6, 7 and 8 are marked in the probe $\phi 50 \times 150$, and points $9,10,11$ and 12 are marked in the probe $\phi 75 \times 225$. Fig. 7 shows the video image of the vapor film position in 1.75 seconds after the immersion of the probe $\phi 75 \times 225$ into the water. Fig. 7 clearly shows that the movement of vapor film does not satisfy the assumption of axisymmetric quenching of the probe, which will later be introduced. This assumption will affect the accuracy of the final solution. During the iterative estimation of the heat transfer coefficient, the computer solution model used experimental results of temperature measurement to minimize errors between computed calculations and measured temperature values in the same place. 


\section{Computer setting of the problem}

According to the adopted assumptions, the test material is homogeneous and isotropic, heat transfer through the cylinder is two-dimensional, axisymmetric and unsteady, whereas the temperature rate of cooling fluid during quenching is constant. Since physical properties of the probe depend on the temperature, the problem is nonlinear. Differential equation of heat conduction in cylindrical coordinates, which describes these problems, has the following form:

$$
\frac{\partial \vartheta}{\partial t}=\frac{\lambda(\vartheta)}{\rho(\vartheta) \cdot c(\vartheta)}\left[\frac{1}{r} \cdot \frac{\partial}{\partial r}\left(r \cdot \frac{\partial \vartheta}{\partial r}\right)+\frac{\partial}{\partial z}\left(\frac{\partial \vartheta}{\partial z}\right)\right] .
$$

It states that: $\vartheta(r, z, t)$ is unsteady temperature field, whereas $\lambda(\vartheta), \rho(\vartheta), c(\vartheta)$ are physical properties of the probe, [12]. The initial condition represents the temperature distribution $\vartheta(r, z, t=0) \approx 850^{\circ} \mathrm{C}$ at each point of each probe. A simplified computational domain is shown in Fig. 8. The boundary conditions for this problem are as follows, [12]:

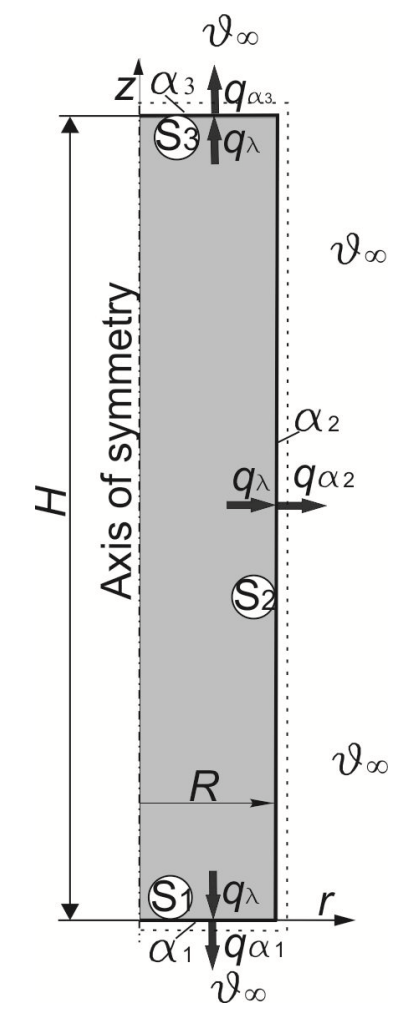

Fig. 8 Computational domain

$$
\begin{aligned}
& \left(\frac{\partial \vartheta(r, z, t)}{\partial r}\right)_{r=0}=0, \text { axial symmetry, } \\
& -\lambda(\vartheta)\left(\frac{\partial \vartheta}{\partial z}\right)=\alpha_{1}(0, t) \cdot\left(\vartheta(r, 0, t)-\vartheta_{\infty}\right), \quad z=0, \text { and } 0 \leq r<R, \\
& -\lambda(\vartheta)\left(\frac{\partial \vartheta}{\partial r}\right)=\alpha_{2}(z, t) \cdot\left(\vartheta(R, z, t)-\vartheta_{\infty}\right), \quad r=R, \text { and } 0<\mathrm{z}<H, \\
& -\lambda(\vartheta)\left(\frac{\partial \vartheta}{\partial z}\right)=\alpha_{3}(H, t) \cdot\left(\vartheta(r, H, t)-\vartheta_{\infty}\right), \quad z=H, \text { and } 0 \leq r<R .
\end{aligned}
$$


Equations (3), (4) and (5), $\alpha_{1}(0, t), \alpha_{2}(z, t)$ and $\alpha_{3}(H, t)$ are the unknown heat transfer coefficients on the particular surfaces, which are described by the function $\alpha(z, t)(0 \leq z \leq H)$ that presents the object of the research. The study problem belongs to inverse problems of heat conduction, or ill posed problems, so that the problem solution adds up to a sufficiently accurate estimate of the unknown heat transfer coefficient imposed on the outer surface of the cylinder.

\subsection{Computer algorithm solution}

Computer solution model, [9] and [11], was created in cooperation with Dr. Imre Felde of the Faculty of Informatics, Technical University of Obuda in Budapest. A computer model of the task is based on hybrid optimization algorithms. The algorithm used in the paper is a combination of direct numerical analysis (FEM), non-dominant sorting genetic algorithm (NSGA II), [8] and Levenberg Marquardt method (LMM) [3]. The algorithm first uses NSGA II, which, in relation to client/server to FEM and on the condition of error minimization, gives half-solution of the heat transfer coefficient. Subsequently, the second LMM algorithm takes over the last NSGAII solution, which, in relation to client/server to FEM, finishes up the final solution, also on the condition of error minimization. Fig. 9 shows flow diagram of the solution algorithm.

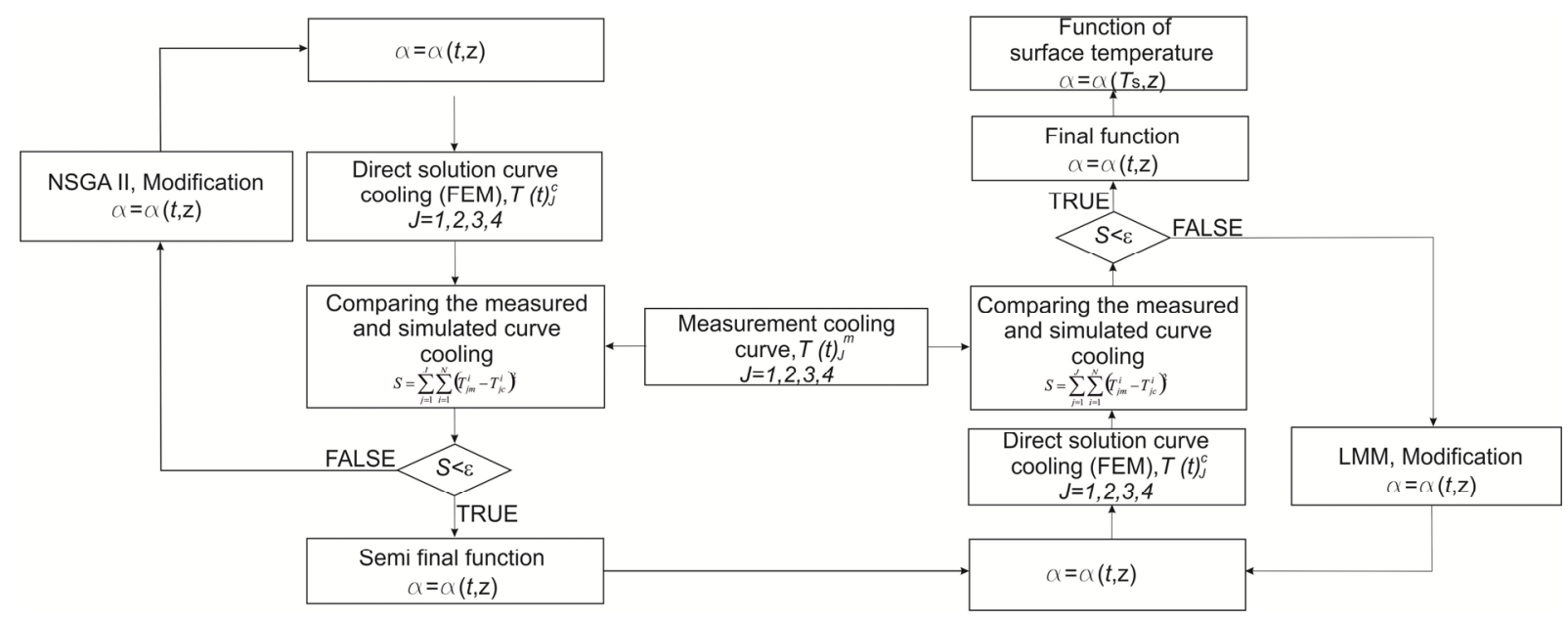

Fig. 9 Applied hybrid algorithm solution

Current heat transfer coefficient $\alpha(t, z)$ is determined in a way that three points are selected on the outer surface of the probe in the $2 \mathrm{D}$ computational domain. Estimated points of time functions are selected horizontally, opposite to measuring point or near the measuring point, as shown in Fig. 10. In this way, three time functions of the heat transfer coefficient are formed, $f_{1}(t), f_{2}(t)$, and $f_{3}(t)$, i.e. three parallel 1D search points. The three functions are found using two for loops. The outer loop is a time loop $\left(t_{1}, \ldots . t_{k}\right)$, where $k$ is the number of carefully selected time steps where heat transfer coefficient is requested. The inner loop is the height of the $z$ probe. Subsequently, these three functions are linear 3D interpolated/extrapolated and in the form of function $\alpha(t, z)$, applied to the outer surface of the cylinder as the boundary conditions of FEM. 


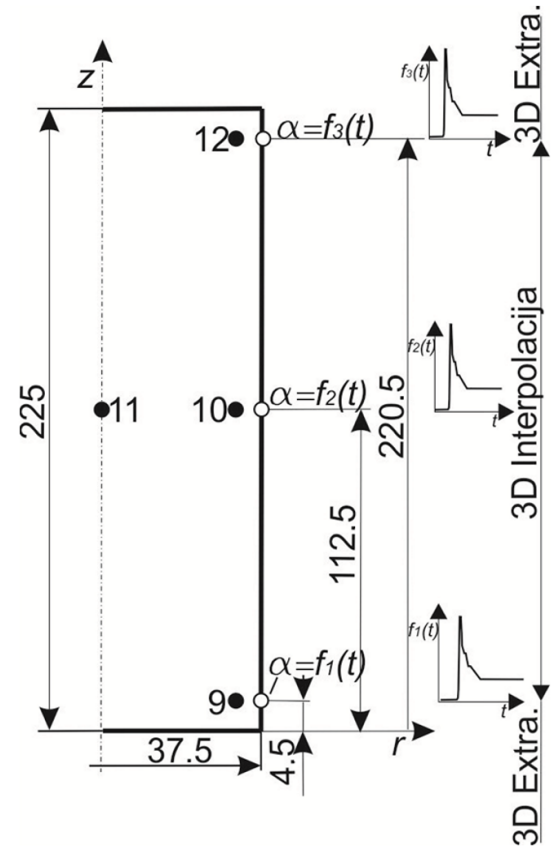

Fig. 10 The position of search points $\alpha(t)=f_{i}(t), i=1,2,3$

Example of search results is a text grid file in Fig. 11. The first row represents the time moments of the search, while other rows represent three heights of the $z$ probe. The last three rows represent time functions $f_{1}(t), f_{2}(t)$, and $f_{3}(t)$.

$\%$ Grid time htc $0.00 .1125 \quad 0.225$

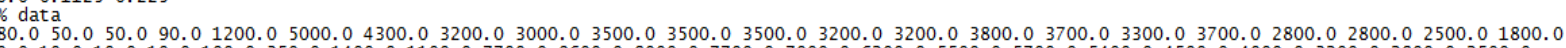

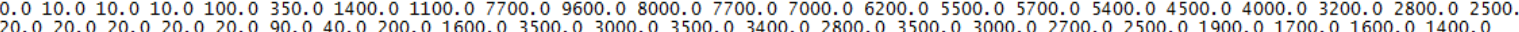

Fig. 11 Text grid file of the search results of heat transfer coefficient during quenching of the probe $\phi 75 \times 225$ in $40{ }^{\circ} \mathrm{C}$ water

Matlab/Comsol software was used to estimate the heat transfer coefficient between server/client. Fig. 12 shows the Pareto fronts during the search, which is divided into an appropriate number of subsets while browsing heat transfer coefficient for all three dimensions of the probe in the same chart. The number of Pareto optimal fronts is determined by the search algorithm itself, according to the number of local optima.

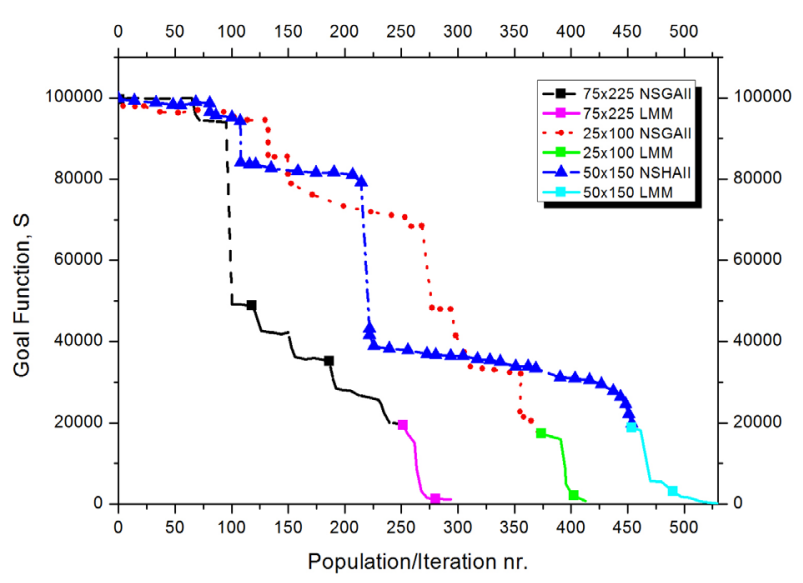

Fig. 12 Pareto fronts of search flow of the heat transfer coefficient for all three probe dimensions

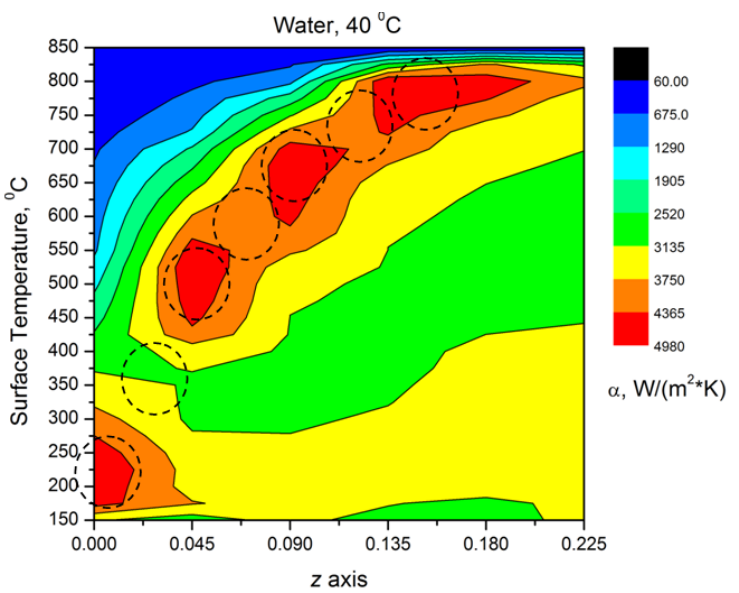

Fig. 13 Solution contour lines of the heat transfer coefficient for the probe $\phi 75 \times 225$ 
The first curve to the left in Fig. 12 corresponds to the Pareto optimal solution in Fig 13. This picture shows the contour lines of the four expressed local maxima and three local minima (seven circles) corresponding to the number of Pareto optimal subsets. The population size is between 250 and 475, depending on the probe dimension. The smaller diameter probes need a larger population, because the smaller diameters have bigger local optima and cooling rate. The results of heat transfer coefficient $\alpha(t, \mathrm{z})$ for three dimensionally different probes are given in the next section.

\section{Analysis and comparison of the obtained results}

\subsection{The quenching of the probe $\phi 25 \times 100$}

The results of $1 \mathrm{D}$ search of heat transfer coefficient during quenching of the probe $\phi 25 \times 100$ in $40{ }^{\circ} \mathrm{C}$ temperature water in marked points are shown in Fig. 14. Fig. 15 shows linear interpolated/extrapolated heat transfer coefficient $\alpha(t, \mathrm{z})$.

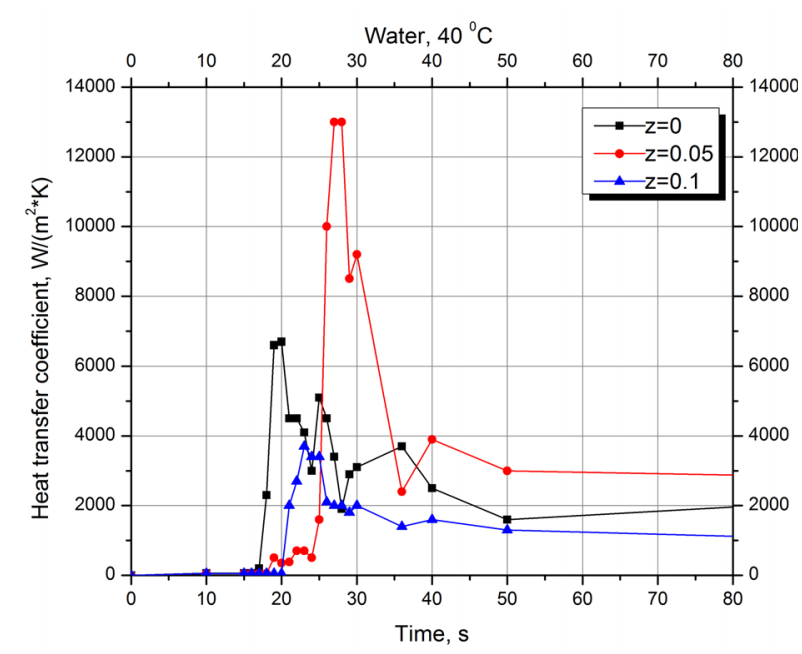

Fig. 14 Time functions $f_{l}(t), f_{2}(t)$, and $f_{3}(t)$ for the probe $\phi 25 \times 100$

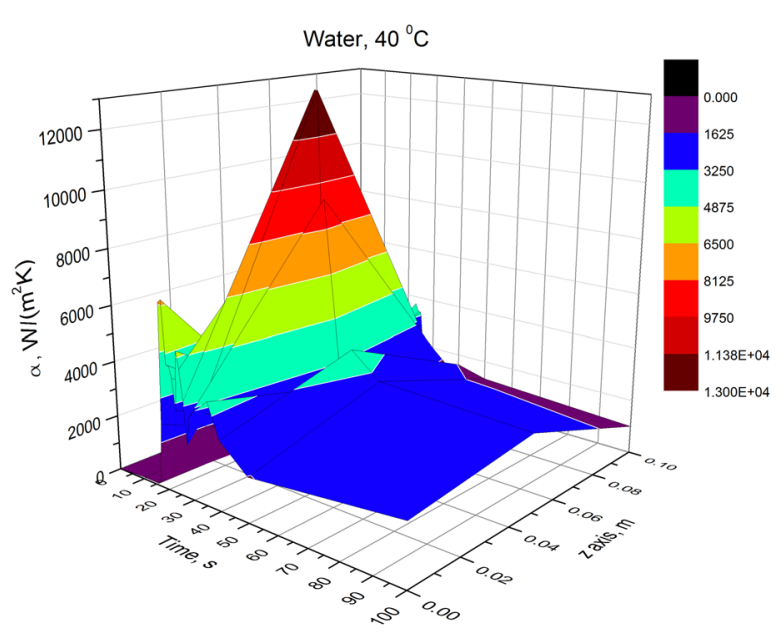

Fig. 15 Heat transfer coefficient $\alpha(t, z)$ for the probe $\phi 25 \times 100$

Fig. 16 shows the results of comparison of measured $\left(\mathrm{TC}_{\mathrm{m}}\right)$ and calculated $\left(\mathrm{TC}_{\mathrm{c}}\right)$ temperatures in all four $(1,2,3,4)$ marked computational domain. The largest local deviation in Fig. 16 $\Delta \vartheta_{\max } \approx 40{ }^{\circ} \mathrm{C}(4.7 \%)$ is shown in the central measuring point (point 3 corresponds to TC 3 ). Other cooling curves have local deviation less than $10{ }^{\circ} \mathrm{C}(1.1 \%)$. The explanation of central deviation is given in the conclusion of the paper. 


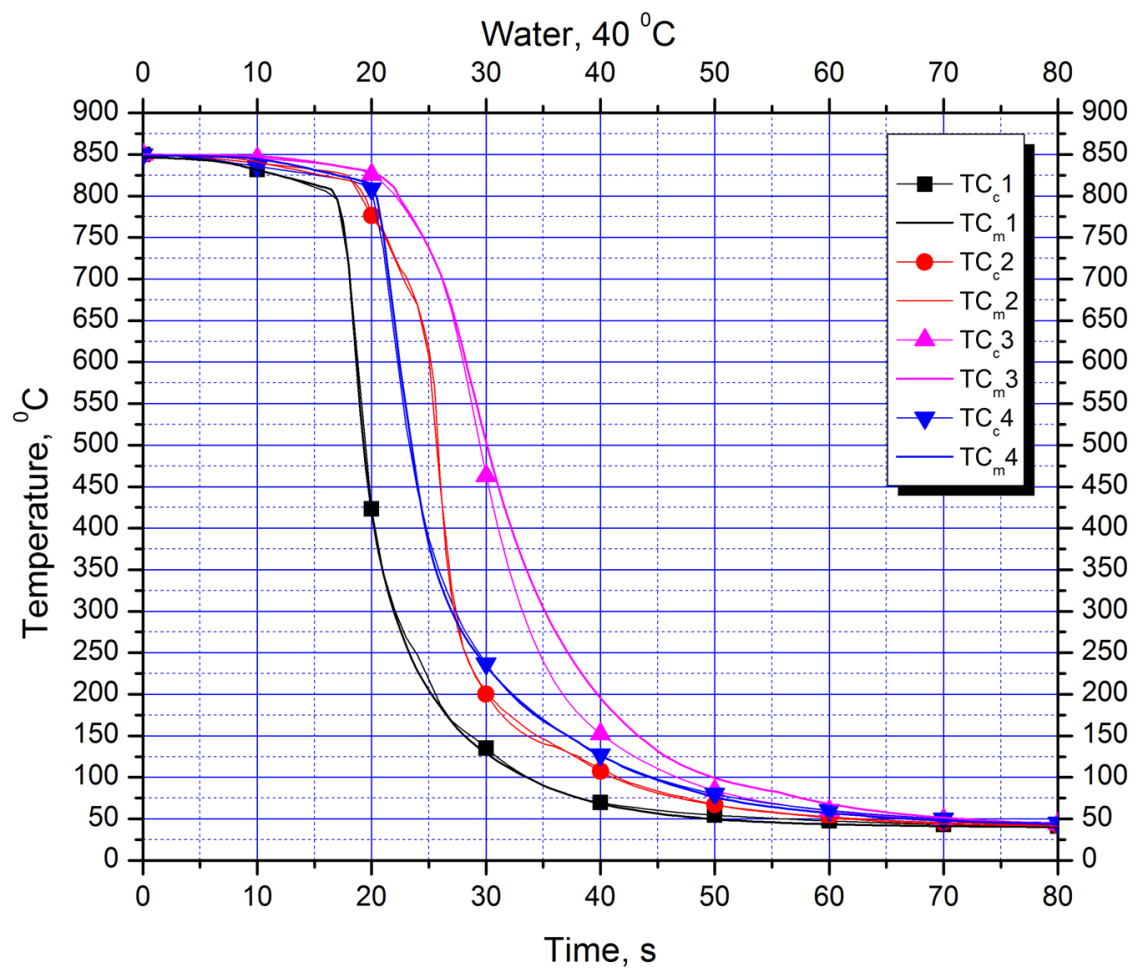

Fig. 16 Comparison of simulated and measured temperatures during quenching of the probe $\phi 25 \times 100$

Fig. 17 and 18 depict heat transfer coefficient as a function of surface temperature and height of the probe, established with its own reparametrization algorithm, [12] and [7]. It was calculated in five values of the $z$ coordinate. With the smaller number of coordinates $z$, there was a danger of losing some of the local extremes.

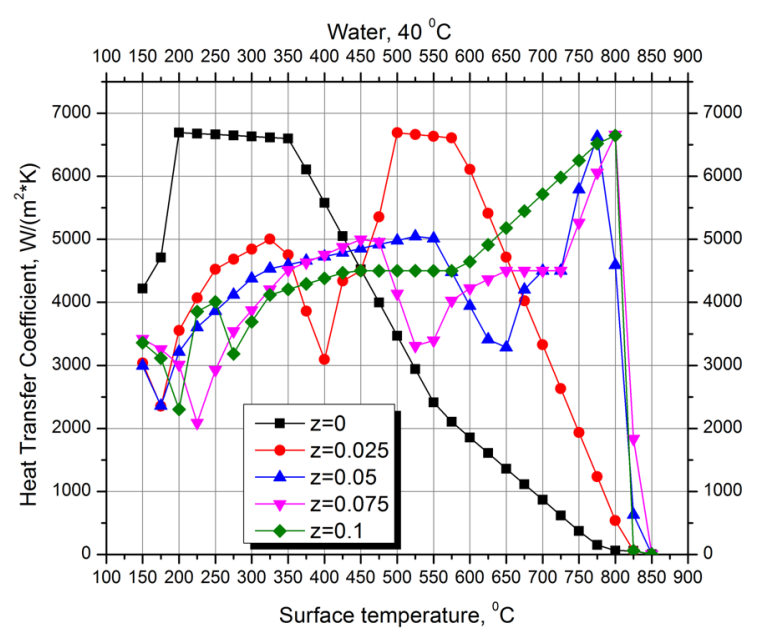

Fig. 17 Parametric display of heat transfer coefficient $\alpha(\vartheta, z)$ for the probe $\phi 25 \times 100$

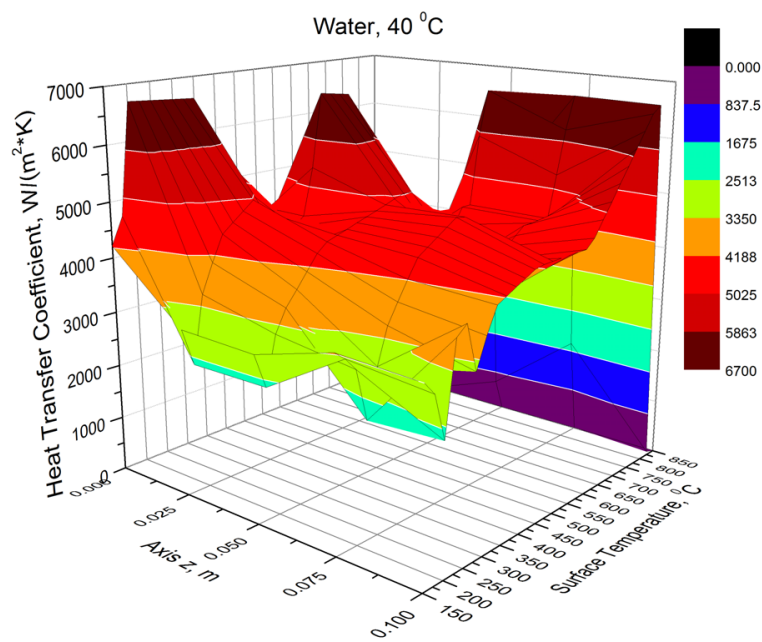

Fig. 18 Linear interpolated heat transfer coefficient $\alpha(\vartheta, z)$ for the probe $\phi 25 \times 100$

\subsection{The quenching of the probe $\phi 50 \times 150$}

The results of 1D search of heat transfer coefficient during quenching of the probe $\phi 50 \times 150$ in $40{ }^{\circ} \mathrm{C}$ temperature water in marked points of the $z$ axis are shown in Fig. 19. The spatial linear interpolation of heat transfer coefficient $\alpha(t, z)$ and $\alpha(\vartheta, z)$ is not given due to limited space of the paper. Fig. 20 depicts the heat transfer coefficient as a function of surface temperature for the probe $\phi 50 \times 150$ calculated in the six values of the $z$ coordinate. 


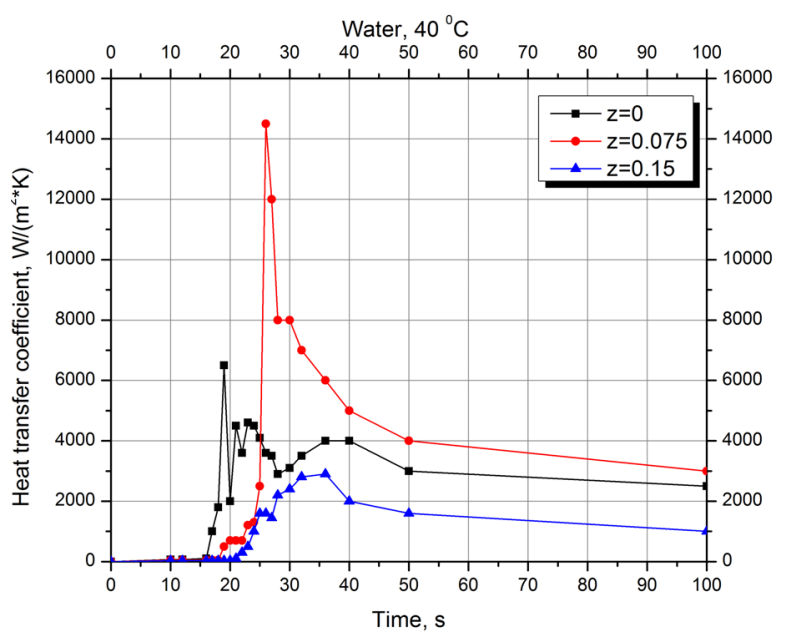

Fig. 19 Time functions $f_{l}(t), f_{2}(t)$, and $f_{3}(t)$ for the probe $\phi 50 \times 150$ in marked points of $z$ axis

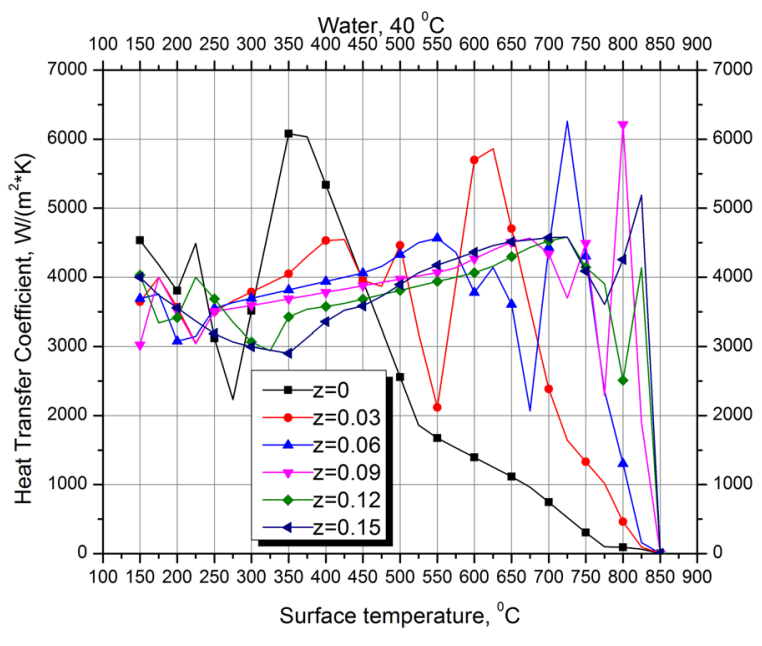

Fig. 20 Heat transfer coefficient $\alpha(\vartheta, z)$ for the probe $\phi 50 \times 150$ in marked point of $z$ axis

Fig. 21 shows the results of comparison of measured $\left(\mathrm{TC}_{\mathrm{m}}\right)$ and calculated $\left(\mathrm{TC}_{\mathrm{c}}\right)$ temperatures in all four observed $(5,6,7,8)$ points of computational domain. The largest local deviation in Figure $21 \Delta \vartheta_{\max } \approx 38{ }^{\circ} \mathrm{C}(4.5 \%)$ is shown in the central measuring point. Other cooling curves have local deviation less than $1.2 \%$.

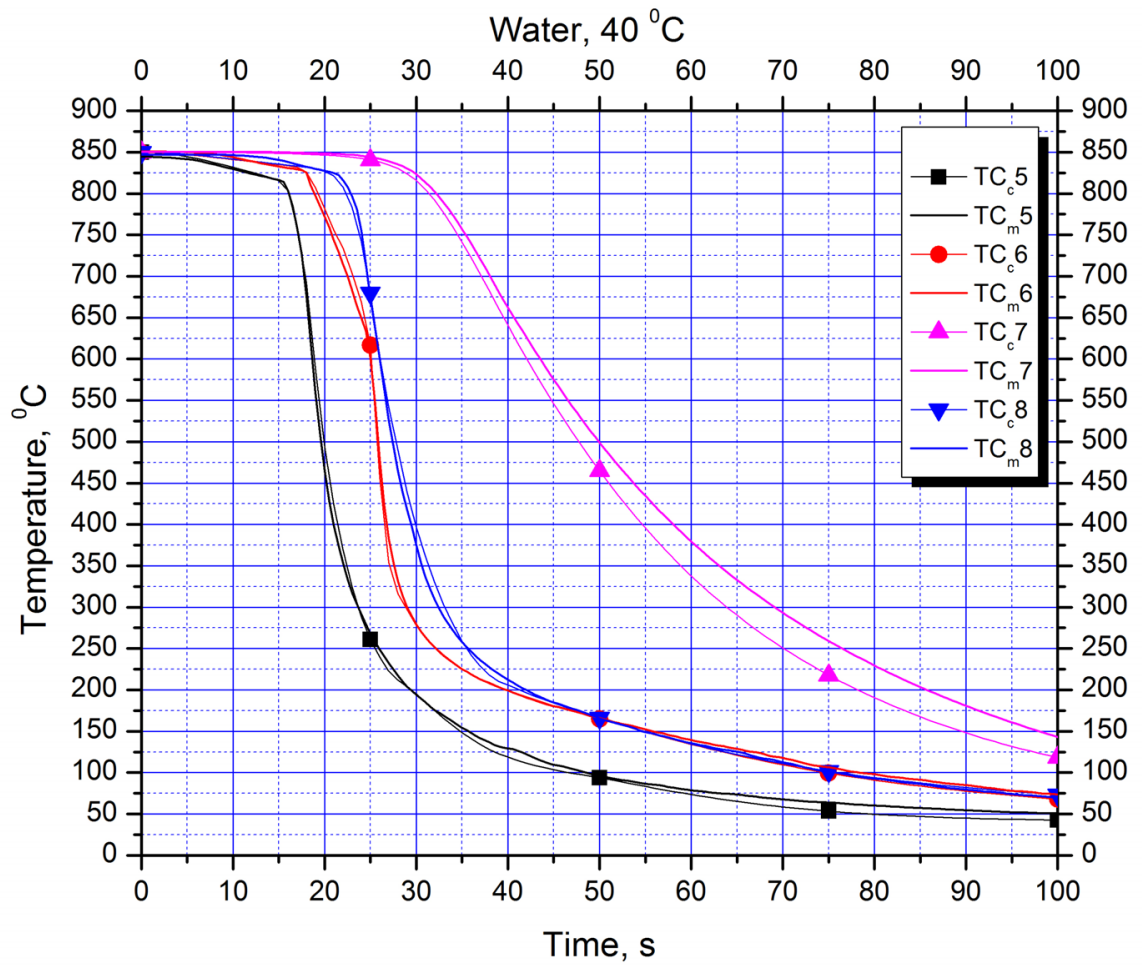

Fig. 21 Comparison of simulated and measured temperatures during quenching of the probe $\phi 50 \times 150$

\subsection{The quenching of the probe $\phi 75 \times 225$}

The results of $1 \mathrm{D}$ search of heat transfer coefficient during quenching of the probe $\phi 75 \times 225$ in $40{ }^{\circ} \mathrm{C}$ temperature water in marked points of the $z$ axis are shown in Fig. 22. Fig. 23 depicts the heat transfer coefficient as a function of surface temperature for the probe $\phi 75 \times 225$ calculated in the six values of the $z$ coordinate. 


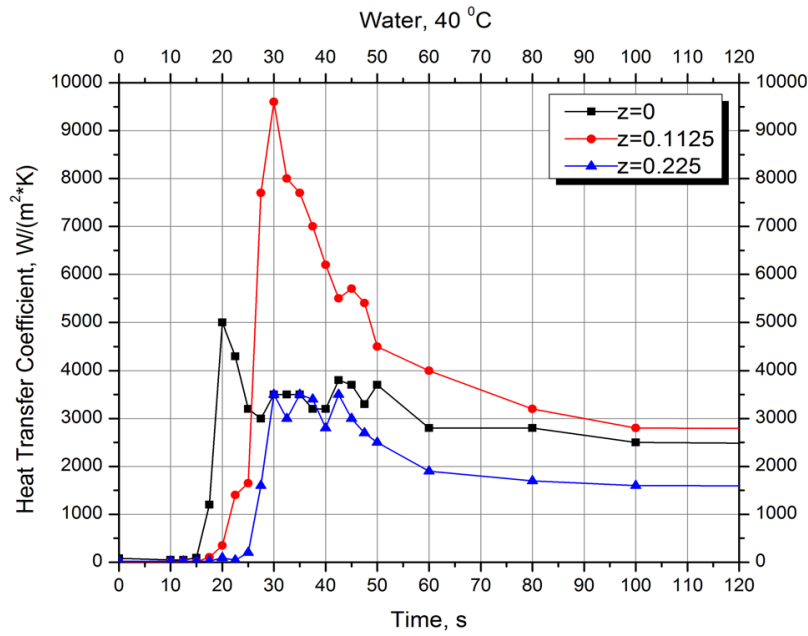

Fig. 22 Time functions $f_{l}(t), f_{2}(t)$, and $f_{3}(t)$ for the probe $\phi 75 \times 225$ in marked points of $z$ axis

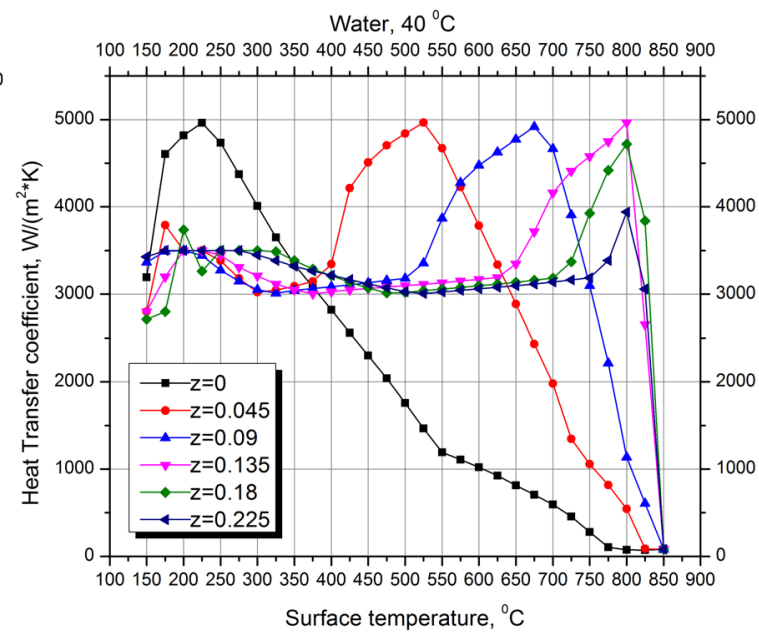

Fig. 23 Heat transfer coefficient $\alpha(\vartheta, z)$ for the probe $\phi 75 \times 225$ in marked points

Fig. 24 shows the results of comparison of measured $\left(\mathrm{TC}_{\mathrm{m}}\right)$ and calculated $\left(\mathrm{TC}_{\mathrm{c}}\right)$ temperatures in all four observed $(9,10,11,12)$ points of computational domain. The largest local deviation in Fig. $24 \Delta \vartheta_{\max } \approx 40{ }^{\circ} \mathrm{C}(4.7 \%)$ is shown in the central measuring point. Other cooling curves have local deviation less than $1.2 \%$.

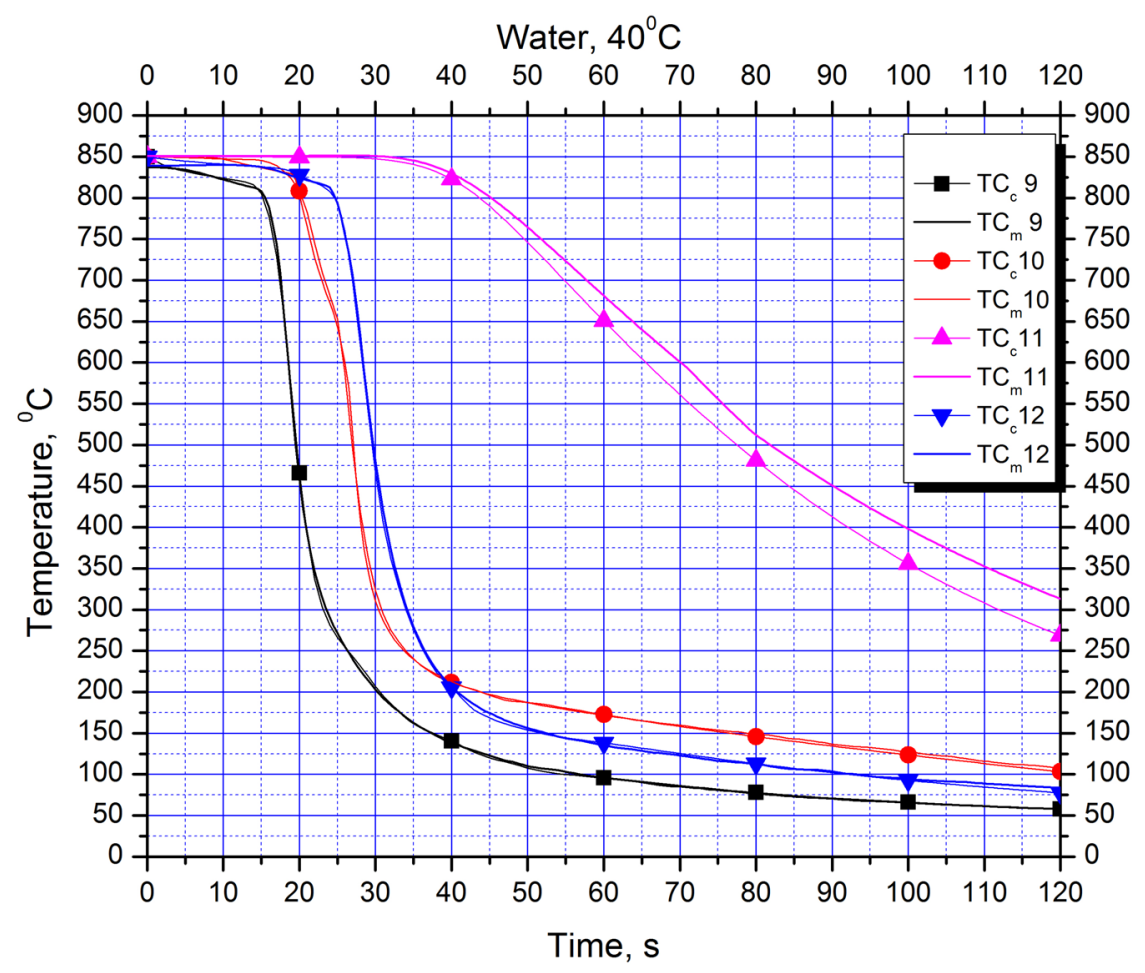

Fig. 24 Comparison of simulated and measured temperatures during quenching of the probe $\phi 75 \times 225$

Figures 14, 19 and 22 local heat transfer coefficients at height $z=H / 2$ of each probe have expressed extremes due to lower influence of heat transfer of probes to water, whereas heat transfer base to water has pronounced effect on heat transfer coefficients at heights $z=0$ and $z=H$. Figures 17, 20 and 23 local heat transfer coefficients are not expressed at height $z=H / 2$. The reason is insufficient number of linear interpolations of the heat transfer coefficient at specific heights of $\mathrm{z}$ axis, which cuts certain peaks. 
The common review of dependence of heat transfer coefficient on diameter and surface temperature at height $z=H / 2$ of each probe is shown in Fig. 25.

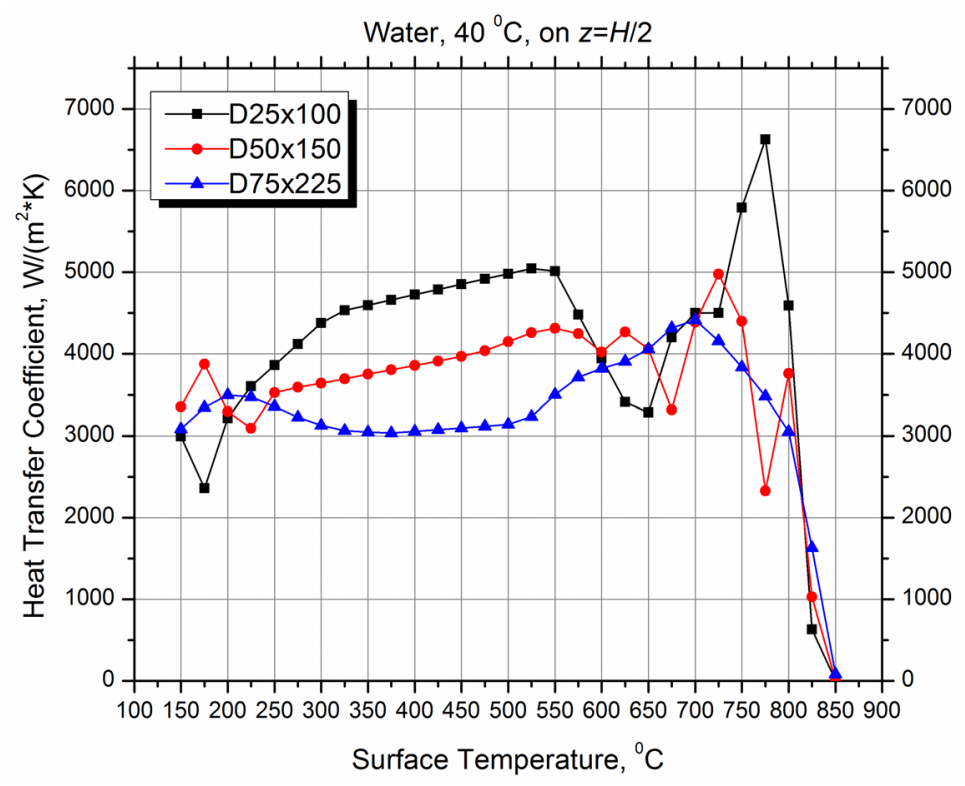

Fig. 25 Heat transfer $\alpha(\vartheta, D)$ at a height $H / 2$

The maximum values of local heat transfer coefficients from lower to higher probe diameter are $6700,6260,4980, \mathrm{~W} /\left(\mathrm{m}^{2} \mathrm{~K}\right)$.

\section{Conclusion}

In order for results of heat transfer coefficient to be in acceptable boundaries, it was necessary to provide quality guidance of experimental work, as well as computer simulations of conducted experiments. The common observation for all the obtained heat transfer coefficient solutions is reflected in the deviation of the measured and simulated cooling curves. Significant deviations are shown in the central measurement point for each simulation. The maximum value of the deviation is $4.7 \%$. Other measuring points were below acceptable $3 \%$. Three cooling curves were obtained with measurements near to the cooling surface of the probe, while the central cooling curve is the furthest one, and is therefore the least sensitive to changes that come within the cylinder surface. The deviation in the measured and calculated cooling curves can be attributed to the introduced assumptions in the 2D axisymmetric computed model. In addition, there are also the accuracy and rate of collected data, as well as experience in manual selection of time steps, which require the value of heat transfer coefficient. Faster quenchants have strong dynamics of the vapor film, which caused the increase in number of search times, so as to describe the cooling curves more accurately, or acquire local extremes of heat transfer coefficient. Novelties used in the paper are reflected through the experimental and simulation part of the paper. In the experimental part of the paper, the novelty is construction of measuring equipment that provides the constant flow rate of the cooling fluid around the test cylinder, and also the test cylindrical probes are improved from two, [1], to four, [12], thermocouples arranged within the probe. The simulation part of the paper is reflected through the application of hybrid algorithm for determining the heat transfer coefficient in 2D axisymmetric inverse heat conduction problem, [11]. Finally, we expanded the knowledge on numerous realistic values of heat transfer coefficient for three dimensionally different test cylinders. 


\section{REFERENCES}

[1] Galović, A., The contribution to the theory of heat exchange between fluidized bath and immersed fixed wall, PhD Thesis, Faculty of Mechanical Engineering and Naval Architecture, Zagreb, 1985.

[2] Liščić, B. and Tensi H.M, Luty W., Theory and Technology of Quenching, Springer Verlag, 1992. https://doi.org/10.1007/978-3-662-01596-4

[3] Özisik, M. N. and Orlande, H. R. B., Inverse heat transfer fundamentals and applications, Department of Mechanical Engineering, North Carolina, State University, 2000.

[4] Kim, H. K., Oh, S. I.: Evaluation of heat transfer coefficient during heat treatment by inverse analysis, Journal of Material Processing Technology, Vol. 112, 2001, pp. 157-165. https://doi.org/10.1016/S0924-0136(00)00877-3

[5] Liščić, B.: Critical Heat -Flux Densities, Quenching Intensity and Heat Extraction Dynamics During Quenching in Vaporizable Liquids, Heat Treatment of Metals, 2004. 2. p.p. $42-46$

[6] K. Arimoto, C. Jin, S. Tamura, K. Funatani, M. Tajima, Verification of Inverse Quench-Hardening Phenomena in Bearing Steel Specimens by Experiment and Computer Simulation, 14th Congress of International Federation for Heat Treatment and surface Engineering (October 26-28, 2004 Shanghai, China, p.p. 465-470

[7] Hrnjica, B. and Jurković, M. Modelling and optimization of the tool stress in drilling process by evolution algorithms, Academic Journal of Manufacturing Engineering, Vol. Issue 2/2007, Bucharest

[8] Deb, K., Multi-Objective Optimization using Evolutionary Algorithms, Wiley, West Sussex, United Kingdom. 2009.

[9] Felde, I., Réti, T., Sarmiento, G., Smoljan B. and A. Deus, Analysis of a numerical method developed for estimation of the heat transfer coefficient obtained during quenching, NETSU SHORI Journal of the Japan Society for Heat Treatment, Vol. 49 (2), 2009, p. 816-819.

[10] Hernández-Morales B., Vergara-Hernández, H.J., Solorio-Díaz, G., Totten, G.E.: Experimental and Computational Study of Heat Transfer During Quenching of Metallic Probes, Evaporation, Condensation and Heat transfer, Amimul Ahsan, ISBN 978-953-307-583-9, p.p 49-68, September, 2011.

[11] Felde, I., Estimation of Thermal Boundary Conditions by using Hybrid Inverse Approach, Materials Science Forum, ISSN: 1662-9752. Vol. 812. pp 419-424, 2015.

[12] Behrem, Š., The influence of the wetting kinematics and cylindrical probe diameters on the heat transfer coefficient during steel quenching, PhD Thesis, University of Bihac, Faculty of Technical Engineering, 2015.

[13] Melhem Omar, A., Sahin, Ahmet Z, Yilbas Bekir, S., Entropy generation due to external fluid flow and heat transfer from a cylinder between parallel planes, Thermal science, Volume 21, Issue 2, 841-848, 2017. https://doi.org/10.2298/TSCI141104068M

Submitted: $\quad 28.11 .2017$

Accepted: $\quad 15.02 .2018$
Assist. Prof. Šefik Behrem Assist. Prof. Bahrudin Hrnjica University of Bihac, Faculty of Technical Engineering Dr. Irfana Ljubijankića bb., 77000 Bihać Bosnia and Herzegovina 